
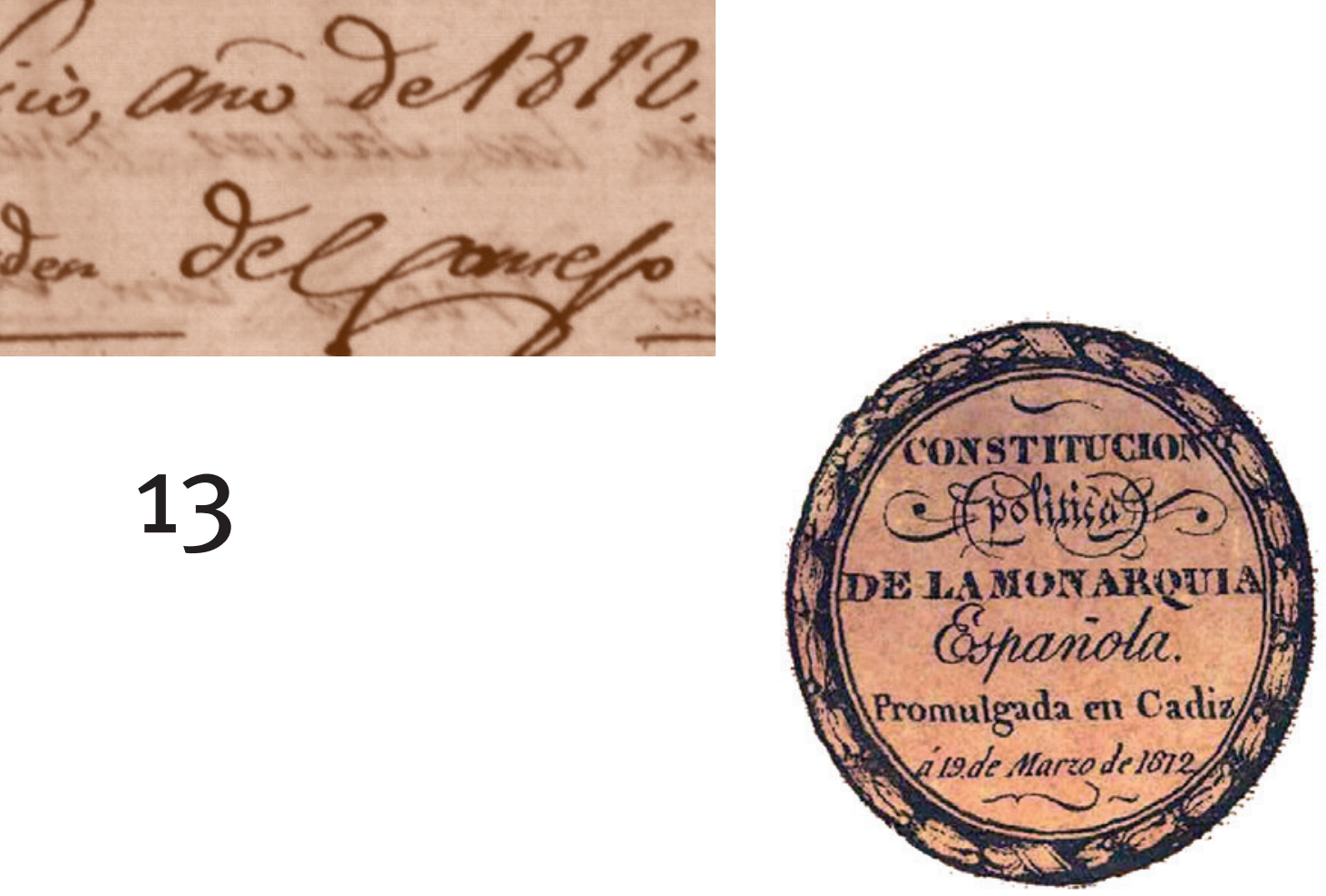

13

romulgada en Cadiz
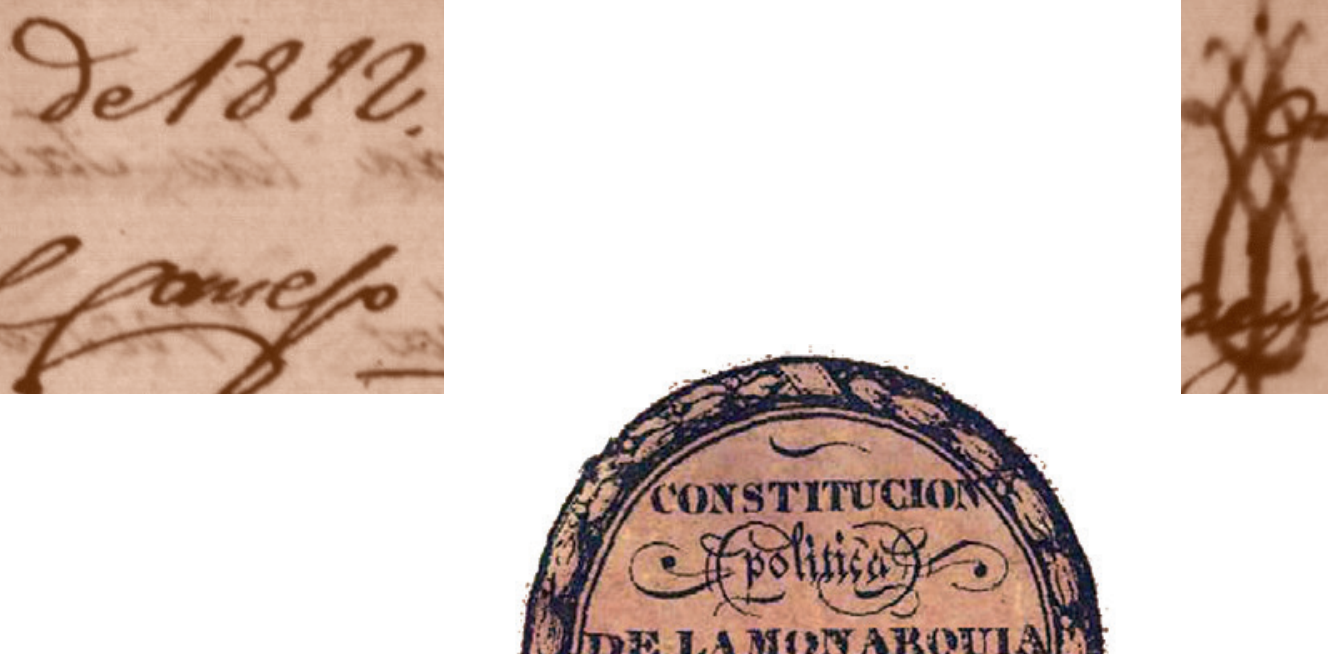



\section{Colección $\mathbf{I m u d}$ \\ n. ${ }^{\text {13 }}$}

\section{LA PROVINCIA DE LA MANCHA Y LA CONSTITUCIÓN DE 1812}





\section{Carlos Chaparro Contreras \\ e Isidro Sánchez Sánchez (eds.)}

\section{LA PROVINCIA DE LA MANCHA Y LA \\ CONSTITUCIÓN DE 1812}

Ediciones de la Universidad

de Castilla-La Mancha

Cuenca, 2021 
LA PROVINCIA de La Mancha y la Constitución de 1812 / editores, Carlos Chaparro Contreras, Isidro Sánchez Sánchez.- Cuenca : Ediciones de la Universidad de Castilla-La Mancha, 2020

341 p. ; 24 cm.- (Almud ; 13)

ISBN 978-84-9044-311-8

1. España - Constitución - 1812 2. Castilla-La Mancha - Historia I. Chaparro Contreras, Carlos, ed. lit. II. Sánchez Sánchez Isidro, ed. lit. III. Universidad de Castilla-La Mancha, ed. IV. Serie

342.4(460)"1812"

946.028

1DSE-ES-G

NHD

(C) de los textos e imágenes: sus autores.

(C) de la edición: Universidad de Castilla-La Mancha.

Edita: Ediciones de la Universidad de Castilla-La Mancha y Centro de Estudios de Castilla-La Mancha.

Colección Almud n. ${ }^{\circ} 13$.

Diseño de la colección:

C.I.D.I. (Universidad de Castilla-La Mancha).

unte Unión de Edtorlales
Universitarias Españolas nacional.

Esta editorial es miembro de la UNE, lo que garantiza la difusión y comercialización de sus publicaciones a nivel nacional e inter-

ISSN: $1988-0979$

I.S.B.N.: 978-84-9044-311-8 (Edición impresa)

I.S.B.N.: 978-84-9044-434-4 (Edición electrónica)

D.O.I.: http://doi.org/10.18239/alm_2021.13.00

D.L.: CU 248-2019

Composición: Compobell S.L.

Impresión: Gráficas Izquierdo

Hecho en España (U.E.) - Made in Spain (U.E.)

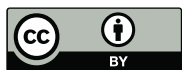

Esta obra se encuentra bajo una licencia internacional Creative Commons CC BY 4.0.

Cualquier forma de reproducción, distribución, comunicación pública o transformación de esta obra no incluida en la licencia Cretative Commons CC BY 4.0 solo puede ser realizada con la autorización expresa de los titulares, salvo excepción prevista por la ley. Puede Ud. acceder al texto completo de la licencia en este enlace: https://creativecommons.org/licenses/by/4.0/deed.es 


\section{ÍNDICE}

Presentación ..................................................................................

Gabino Marco Solera, Carmen María Montalbán Martínez y Antonio Ruiz Lucas

Las Cortes y la Constitución de Cádiz: contenidos sociales y esperanzas populares

Juan Sisinio Pérez Garzón

La Constitución de 1812

Enrique Belda Pérez-Pedrero

Guerra y revolución en La Mancha Ángel Ramón del Valle Calzado

El Partido de Alcaraz a finales del Antiguo Régimen

65 Carmen Hernández López y Francisco García González

"Napoleón emperador" y el destino del Partido de Almagro......... José Gregorio Cayuela Fernández

La Mancha, 1812: El partido judicial de Villanueva de los Infantes Lucía Crespo Jiménez

Representación y educación político-popular en las ceremonias y fiestas de proclamación y jura de la Constitución de 1812 en La Mancha

Carlos Chaparro Contreras

La crisis del Antiguo Régimen en La Mancha (1787-1808). El caso de Villanueva de los Infantes y su partido.... Carlos Javier Rubio Martínez 
Los manchegos que auparon a la "Pepa"

Enrique Jiménez Villalta

Almadén y la Constitución de Cádiz (1812-1814)

245

Julián Prior Cabanillas

El padre Agustín de Castro y la prensa periódica

273 Isidro Sánchez Sánchez 


\title{
EL PARTIDO DE ALCARAZ A FINALES DEL ANTIGUO RÉGIMEN ${ }^{1}$
}

\author{
CARMEN HERNÁNDEZ LÓPEZ \\ FRANCISCO GARCÍA GONZÁLEZ \\ Seminario de Historia Social de la Población \\ FaCUlTad DE Humanidades de Albacete (UCLM)
}

En el siglo XVIII la llegada de las ideas ilustradas a España fue forjando una urgente necesidad de cambio social. Cambio de un modelo feudal en el que los estamentos privilegiados, nobleza e iglesia, monopolizaban poder, tierras y riqueza, pero donde la inmensa mayoría de la población era de escaso tener. Cambio de una sociedad eminentemente agraria y marcada por un profundo desequilibrio al estar completamente invertida la distribución de la tierra y el producto derivado de ella como ocurría sobre todo en regiones como la actual Castilla-La Mancha. En este sentido, centrándonos en un caso concreto como era el Partido de Alcaraz, trataremos de aproximarnos como una especie de laboratorio a la situación que caracterizaba a estas zonas entre finales del Antiguo Régimen y el comienzo del siglo XIX.

\section{TERRITORIO Y REDES DE POBLACIÓN}

El Partido de Alcaraz ocupaba en el siglo XVIII el extremo noroccidental de la actual provincia de Albacete. Desde el punto de vista paisajístico o del territorio presenta dos sectores bien diferenciados. Mientras que en la parte septentrional el relieve es poco pronunciado,

1 El presente trabajo forma parte del proyecto de investigación: "Familia, curso de vida y reproducción social en la España centro-meridional, 1700-1860", referencia HAR201021325-C05-03, del que es Investigador Principal Francisco García González y ha sido posible gracias a la financiación concedida por el Ministerio de Economía y Competitividad. 
cuyas altitudes 2 no superan los 750-1.100 metros, con elevadas mesetas como las de El Bonillo, Munera o El Ballestero, el sur es la parte plenamente serrana, con altitudes que alcanzan los 1.789 metros (Pico de la Almenara). Unidad marginal de las Béticas, nos situamos en una zona de transición con la Meseta. Completa este paisaje una variada vegetación y una riquísima flora -más de mil especies diferentes- que sin duda representaron un enorme potencial para ser utilizados como hierbas medicinales, plantas aromáticas o sencillamente como tintes, tanto es así que en las Relaciones de Tomás López llegan a decir que "sin duda se podría formar un Jardín Botánico bien surtido ${ }^{3}$ "
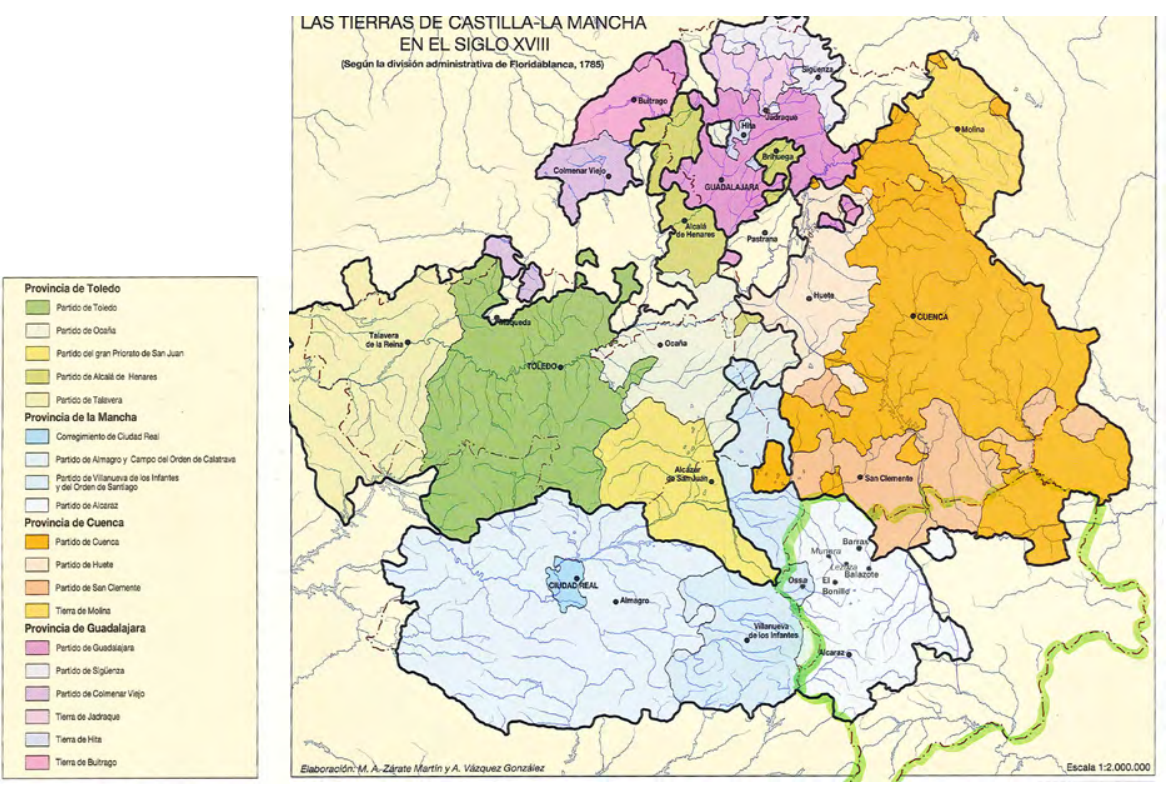

Fuente: Atlas de Castilla-La Mancha, Toledo, Junta de Comunidades de Castilla-La Mancha, 1986, pág. 60.

Fernando Colón, ilustre viajero que a finales del primer cuarto del siglo XVI recorría la zona septentrional del Partido, nos dejaba descripciones de la zona como ésta: El Bonillo "es tierra doblada e de montes e

2 En los términos de Alcaraz y Villapalacios comienzan las estribaciones montañosas con cierta entidad, como el pico de la Almenara (1.789 m.), El Gallinero (1.630 m.) y la Sierra del Agua $(1,600 \mathrm{~m}$.)

3 F. Rodríguez de la Torre y J. Cano Valero, Relaciones Geográfico-históricas de Albacete (1786-1789) de Tomás López, Albacete, I.E.A, 1987, p. 112. 
enzinares e robledales.... e savinares; Munera es tierra de cerros e montes e savinares, y de Munera a Villarrobledo hay cinco leguas llanas las dos primeras son de montes de enzinares e todo este camyno es de atochares e de tierras de labranças salvo que salyendo del lugar (Munera) ay algunos barrancos" 4 .

En conjunto, y como se indicaba de forma muy expresiva a finales del siglo XVIII en las Relaciones de Tomás López referidas a la ciudad de Alcaraz, "todo el territorio de esta ciudad es montuoso, áspero y quebrado, excepto por la parte Norte; generalmente está poblado de encinas, romeros, pinos, sabinas, fresnos y jara... Las Sierras más principales que ahi dentro de esta jurisdicción se nombran de Almenara; son muy eminentes y quebradas y separan las vertientes de los rios y arroios que van expresados; estas sierras se unen al Padron de Bienservida, después con las del Calar del Mundo incorporandose sin intermisión con las de Segura y Sierra Morena" ${ }^{\text {. }}$.

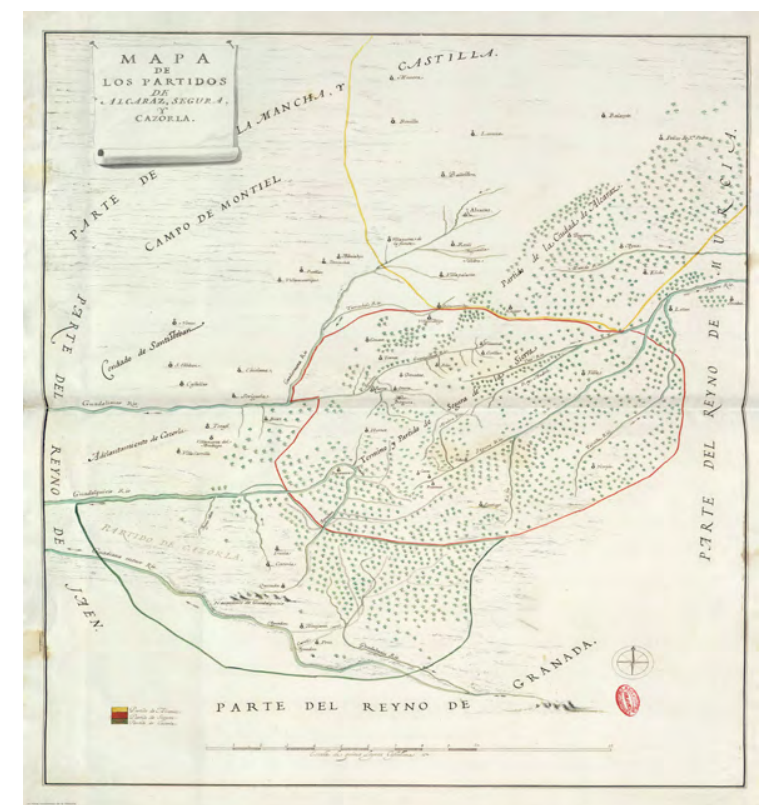

Relation: Carmen López Gómez, Antonio y Manso Porto, Cartografía del siglo XVIII. Tomás López en la Real Academia de la Historia, Madrid, Real Academia de la Historia, 2006, n. ${ }^{\circ} 126$, p. 369.

\footnotetext{
4 F. Colón, Descripción y Cosmografía de España, Madrid, 1908-17, vol. II, pp. 131-145.

5 F. Rodríguez de la Torre y J. Cano Valero, Relaciones Geográfico-históricas .....op. cit., pág. 107.
} 
La conformación de este territorio, en gran medida, es la consecuencia del proceso de reconquista y repoblación medieval llevada a cabo por la Corona castellano-leonesa, un territorio casi desértico y en el que tuvieron un importante papel las órdenes militares, especialmente la de Santiago y los Señores jurisdiccionales.

El Concejo de Alcaraz es una de las primeras circunscripciones que se constituyeron en el siglo XIII. Alfonso VIII dotó a la villa de Alcaraz de un privilegiado Fuero, con amplias libertades y exenciones que sirvieran de estímulo para el poblamiento y desarrollo de esta zona. El modelo elegido para la ocupación de este amplio espacio fue el reparto de solares y tierras aledañas a la villa y a las principales aldeas capturadas, dejando un gran espacio para aprovechamiento comunal de los montes y pastos y entregando a las órdenes o a los Caballeros del séquito real grandes extensiones de tierra. En pocos años el alfoz de Alcaraz ${ }^{6}$ comprendía un gran territorio, que se fue extendiendo a lo largo del siglo XIII para llegar a comprender, durante su primera mitad, gran parte del Campo de Montiel y toda la zona occidental de la actual provincia de Albacete, desde Villarrobledo al calar del río Mundo en Riópar. Posteriormente la Orden de Santiago que ocupa Montiel, irá recortando el término otorgado a Alcaraz y a finales del siglo XV con la pérdida de las Cinco Villas a favor del Conde de Paredes y la emancipación de Villarrobledo, el término se reduce a $4.087 \mathrm{~km}^{2}$.

El proceso de desmembración del Concejo de Alcaraz continuó durante las dos centurias siguientes con la venalidad de las jurisdicciones concejiles. Adquirió su mayor desarrollo en el siglo XVI y la ciudad de Alcaraz perdió sus poblaciones más importantes: Peñas de San Pedro (1537), El Bonillo (1538), Munera (1548), Lezuza (1553), Barrax (1564), Ayna (1565), Villanueva de Alcaraz (1566), Bogarra (1573) y El Ballestero (1694), aunque todas ellas permanecieron bajo la jurisdicción del Corregimiento de Alcaraz, excepto Villarrobledo que pasó a la Gobernación del Marquesado de Villena. Al final, Alcaraz perdió más de la mitad de su término, los núcleos más poblados y productivos, pero ello no supuso la ruptura de la unidad económica y de subsistencia que se pretendió con la creación de aquel gran Concejo medieval, sino que se mantuvo.

La ciudad de Alcaraz destacaba con tareas comerciales, artesanales, burocráticas y administrativas, aunque sin perder la influencia del medio rural en el que se inserta. Era cabeza de Partido y de Vicaría, lo que sin

6 Para una mayor información sobre el pasado medieval de estas tierras véanse las numerosas publicaciones de Aurelio Pretel Marín. Por ejemplo para las villas de El Campo de Montiel vid. A. Pretel Marín, "Villazgo de El Bonillo: precedentes, proceso y consecuencias" en Privilegios de El Bonillo en el siglo XVI, Albacete, IEA, 2001, pp. 13-74. 
duda influía en la atracción de la población aldeana o de las villas para cubrir sus necesidades de consumo y trabajo, lo que hacía de ella un centro de poder, bien por el dominio jurisdiccional que ejercía a modo de señorío colectivo sobre sus aldeas, bien de forma indirecta por medio de los grupos e instituciones privilegiadas que ahí residían (nobleza, clero..), pero en cualquier caso sus posibilidades de futuro dependían del campo.

A lo largo del siglo XVIII se producirá una continua redistribución del poblamiento dentro del interior del Partido $^{7}$, tanto de la población de la ciudad hacia su zona más próxima, como entre otras villas y aldeas más alejadas, de tal forma que a medida que avanzaba esta centuria el poblamiento rural aldeano fue aumentando, hasta llegar a sobrepasar incluso la población de la ciudad de Alcaraz $^{8}$. Como consecuencia, el poblamiento presentaba una gran asimetría derivada del elevado nivel de diseminación, sobre todo en la sierra, de tal manera que a lo largo del territorio existirá una variada y heterogénea gama de núcleos de poblamiento: ciudad, villas, aldeas, lugares, ventas, caserías, granjas, cortijos, casas de labor, heredamientos, cotos redondos, etc, formas características del hábitat disperso en el Partido de Alcaraz.

Con todo, el Partido de Alcaraz y las comarcas que en él se integran, presentaban una de las constantes históricas que vienen repitiéndose desde los primeros recuentos poblacionales, la existencia de extensas áreas vacías y su escasa densidad de población. Así, hacia 1530 se estimaban 3,27 los habitantes por $\mathrm{km}^{2}$ para el Concejo de Alcaraz, cifra que apenas superaba los cuatro $(4,18)$ hacia 1591. A mediados del siglo XVIII la comarca apenas sobrepasaba los cinco habitantes, un escaso 5,2 $\mathrm{hab} / \mathrm{km}^{2}$, y en 1787 se llegaría a los 6. Para las tierras manchegas, los datos son muy similares, en 1752 tan solo eran 5,47 hab $/ \mathrm{km}^{2}$, siendo El Bonillo y Villarrobledo las villas que presentaban una mayor densidad de población, 8 hab. $/ \mathrm{km}^{2}$. En cualquier caso, cifras de las más bajas de España.

Además las malas comunicaciones contribuyeron indudablemente al aislamiento de estas comarcas, como así manifestaban en 1782 los vecinos de la villa de Bogarra, los caminos decían, "eran agrios, penosos y que es necesario, hora y media, o dos horas, para traspasar y andar una

7 Para profundizar en estos temas vid. F. García González, La Sierra de Alcaraz en el siglo XVIII. Población, familia y estructura agraria, Albacete, IEA, 1998.

8 Así en el vecindario de 1784, el único recuento que para todo el setecientos distingue entre la población residente en el casco urbano del resto, la ciudad contaba con 663 vecinos frente a los 504 registrados en las caserías y 748 en las aldeas. Archivo Municipal de Alcaraz (en adelante AMAlc), leg. 380, Vecindario General del Casco de esta ciudad, año de 1784. 
legua" 9 y es que a pesar de tratarse de una zona de interior, el territorio se caracterizará por ser una zona periférica, tanto si se contemplaba desde la meseta como desde Andalucía o Murcia, prevaleciendo a través del tiempo su carácter de límite, de frontera, como si se hubiesen empeñado en perpetuar el lema medieval del escudo que ostenta la ciudad de Alcaraz: "clavis totius hispaniae et caput extremature".

\section{LA EVOLUCIÓN DEMOGRÁFICA}

A finales del siglo XVI la población en el Partido de Alcaraz se acercaba a los treinta mil habitantes (28.841 habitantes). En la comarca de Alcaraz no alcanzaba los once mil habitantes (10.950) y en su zona manchega, Villarrobledo superaba los seis mil, siendo la más poblada de todas estas villas, ya que El Bonillo se acercaba a los tres mil y Lezuza y Munera no llegan al millar de personas (en torno a 850 h. cada una). En la zona centro-sur las villas de Bogarra, Ayna y Peñas de San Pedro se aproximaban a los cuatro mil habitantes, 3.920 (Ver Tabla 1).

En consonancia con la nueva condición adquirida, entre 1530 y 1591 y la positiva coyuntura económica, se destaca un primer periodo de crecimiento de la población que podemos considerar extraordinario, puesto que supone un 45 por ciento de incremento y que pondríamos en relación con la existencia de una fuerte inmigración. A nivel global, La Mancha experimentó un crecimiento del 20,18 por ciento entre 1561 y 1591 .

Durante los siglos XVI y XVII la población perteneciente al Concejo de Alcaraz experimentó una evolución demográfica análoga al resto de la Corona de Castilla, un periodo de crecimiento y expansión seguido de otro de estancamiento y regresión ${ }^{10}$. En poco más de cincuenta años de 1591 a 1646, pasó de veintiocho mil quinientos habitantes a dieciocho mil quinientos, (una tasa de crecimiento anual de -0,60 en la comarca de Alcaraz). A partir de entonces parece que el volumen poblacional se mantendría estabilizado, aunque con altibajos, como refleja el censo de 1693.

En la explicación del hundimiento demográfico del siglo XVII se conjugan varios factores, como las consecuencias de las epidemias, de la guerra, la expulsión de los moriscos ${ }^{11}$, el declive del sector manufacture-

9 R. Sánchez González, "El partido de Alcaraz a través de las Relaciones del Cardenal Lorenzana”, Al-Basit, núm. 28 (1991), p. 51.

10 Para una aproximación más general vid. F. García González, "La ocupación del territorio. Familia y población”, en F. García González (ed.), Castilla- La Mancha en la Edad Moderna, Ciudad Real, Almud, 2004, pp. 17-52.

11 Según las estimaciones de J. López-Salazar, Estructuras agrarias y sociedad....op. cit., pp. 83-84, la pérdida supondría para Alcaraz y sus aldeas aproximadamente un 7,3 por ciento que puede considerarse como fuerte en relación a otros ejemplos manchegos. 
ro y los movimientos migratorios que jugarían sin duda un papel nada desdeñable. Pero hay que destacar principalmente la incidencia de la sobremortalidad catastrófica en el Partido de Alcaraz que se vio afectado por los ramales epidemiológicos nacionales, tanto el murciano como el andaluz.

\section{TABLA 1}

EVOLUCIÓN DE LA POBLACIÓN POR COMARCAS eN el Partido de AlCaraz. 1530-1860

\begin{tabular}{|c|c|c|c|c|c|c|c|c|}
\hline Comarcas & $\begin{array}{l}1530 \\
\text { vec. }\end{array}$ & $\begin{array}{l}1591 \\
\text { hab. }\end{array}$ & $\begin{array}{l}1646 \\
\text { hab. }\end{array}$ & $\begin{array}{l}1693 \\
\text { hab. }\end{array}$ & $\begin{array}{l}1752 \\
\text { hab. }\end{array}$ & $\begin{array}{l}1787 \\
\text { hab. }\end{array}$ & 1824 & $\begin{array}{l}\text { Censo } \\
\text { de } 1860\end{array}$ \\
\hline $\begin{array}{l}\text { Norte-NE. La } \\
\text { Mancha }\end{array}$ & 1.816 & 13.902 & 9.548 & 12.410 & 15.285 & 19.409 & $\begin{array}{r}\text { Munera: } \\
2.088\end{array}$ & 29.473 \\
\hline $\begin{array}{l}\text { Sur-SE. Sierra } \\
\text { de Alcaraz y sus } \\
\text { aldeas }\end{array}$ & 1.863 & 7.238 & 3.508 & 5.790 & 6462 & 7.687 & 10.664 & 17.812 \\
\hline $\begin{array}{l}\text { Sur-SE. Señorío de } \\
\text { las cinco villas }\end{array}$ & 941 & 3.421 & 2.244 & 2.755 & 2206 & 2.221 & & 6.076 \\
\hline $\begin{array}{l}\text { Centro-SW: Ayna, } \\
\text { Bogarra y Peñas } \\
\text { de San Pedro }\end{array}$ & 740 & 3.920 & 3.268 & 5.685 & & 8.289 & & 7.464 \\
\hline TOTAL & 5.360 & 28.481 & 18.568 & 26.640 & & 37606 & & 60.825 \\
\hline
\end{tabular}

Fuente: Para la comarca manchega de El Campo de Montiel: J. López-Salazar Pérez, Estructuras agrarias y sociedad rural en La Mancha (Siglos XVI-XVII), Ciudad Real, IEM, 1986, pp. 665-675. Para la comarca de Alcaraz: F. García González, La sierra de Alcaraz en el siglo XVIII... op. cit., pp. 395 y 396. Censo de Floridablanca (INE 1987) para los datos de 1787. Para Villarrobledo: A. Sandoval Mulleras, Historia de mi pueblo. Villarrobledo, s. XVIII, Albacete, IEA, 1960, revisado por A. Plaza Simón, Apuntes de Historia, Villarrobledo, 2007 y Gómez López y Cebrián Abellán: “Antecedentes socio-económicos del oriente manchego. Villarrobledo (Albacete), Papeles de Geografía, n $^{\circ}$ 13, pp. 127-140; y para Bogarra: M. P. Molina Gómez, Familia, población y propiedad de la tierra. Los jóvenes en la sierra del Segura albacetense del siglo XVIII, Trabajo de investigación para la obtención del DEA, Murcia, noviembre 2007. Para la comarca de la Mancha: C. Hernández López, La casa en la Mancha oriental. Arquitectura, familia y sociedad rural (1650-1850), Tesis doctoral, Facultad de Humanidades de Albacete, 2009.

Y aunque es evidente el saldo negativo en el siglo XVII, lo importante es que las bases del crecimiento se fueron consolidando, especialmente entre 1654 y 1717. Barrax, Peñas de San Pedro, Lezuza y Balazote 
duplicaron su población entre 1693 y 1787. En la comarca de Alcaraz a pesar de que el siglo XVIII constituyó una época de fuerte crecimiento, dados los bajísimos niveles de partida, en 1752 había un 16,6 por ciento menos de población que en 1591. Es ilustrativo el caso de la villa de Riópar donde en 1747 se decía que "se han aniquilado y caído más de 240 casas de morada desde su primitiva subsistencia hasta hoy... pasando de 300 vecinos a los sesenta que tenía ahora" ${ }^{12}$.

Se puede así afirmar, que para el Partido de Alcaraz los primeros veinte años de la centuria fueron de estancamiento, hasta los años cincuenta de crecimiento atenuado y un crecimiento sostenido a partir de estas fechas centrales del siglo hasta el final. El crecimiento se produjo de forma continuada, pero irregular, con breves etapas recesivas, cada vez menos profundas, a medida que avanzaba el siglo, prueba evidente de que su desarrollo demográfico tendió progresivamente a ser autosostenido.

Las crisis de mortalidad ${ }^{13}$ siguieron siendo importantes en el siglo XVIII, tanto en España como en el Partido de Alcaraz, concretamente en las tierras de La Mancha oriental, entre 1700 y 1799 se produjeron hasta siete crisis de mortandad (Gráfico 1), siendo especialmente intensa la de 1707 en todo el Partido.

Parece ser que hambre y enfermedad infecciosa han configurado conjuntamente la mayoría de las crisis. En el Partido de Alcaraz comprobamos la presencia de una crisis mixta en la que se combina la acción de ambos factores. Una conjunción de adversidades: Guerra de Sucesión, plagas de langosta, epidemias y pobreza se unieron en la grave crisis padecida en el Partido de Alcaraz y en toda España a lo largo del periodo 1707-1712 (Tabla 2). En la villa de El Bonillo el Consejo de Justicia y Regimiento de la villa de El Bonillo llegaron a afirmar que "los vecinos están aniquilados con las plagas de langosta que han padecido" 14 , y solicitaban se les rebajase la contribución junto con la villa de Peñas de San Pedro.

Las plagas de langosta y su acción devastadora sobre cultivos, pastizales y montes eran el preludio de una crisis de subsistencia. En Villarro-

12 AMAlc, leg.488, Exp. 2: "Informe del Estado de las villas del Partido de Alcaraz que solicita el Rey" (1747)

13 El concepto de crisis de mortalidad queda sumergido en estos momentos dentro del más amplio concepto de "crisis demográfica", en el que tienen cabida no sólo los fenómenos de sobremortalidad, sino también aquellos factores que pueden contribuir al descenso o estancamiento de la población, sin su eliminación física directa y afectando a los niveles de celibato definitivo y a las tasas de natalidad y fecundidad marital, en A. Alberola Romá, Catástrofe, economía y política en la Valencia del siglo XVIII, Valencia, Edicions Alfons el Màgnanim, 1999.

14 Archivo Histórico Provincial de Albacete (en adelante AHPA), Sección Protocolos notariales caja 3524, ante el escribano Juan Jiménez (20/07/1709) 


\section{GráFICO 1}

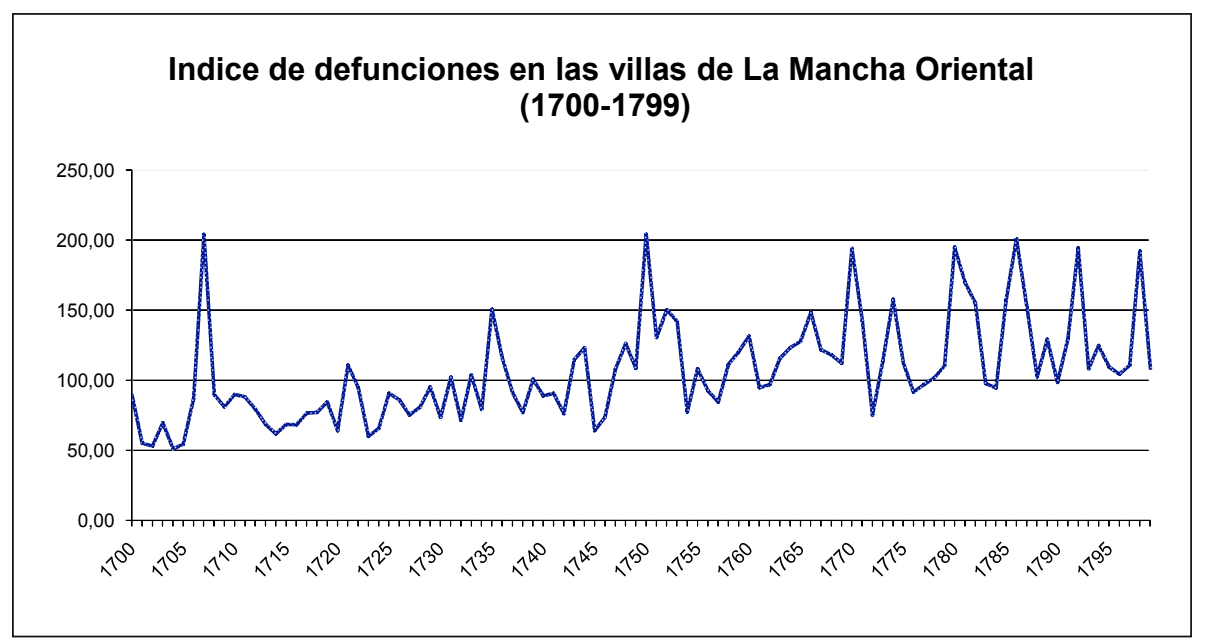

Nota: Índice 100 a partir de la media

Fuente: Archivo Diocesano de Albacete (en adelante ADA). Libros de defunciones de El Bonillo, Lezuza, Munera, Balazote, Barrax y Lezuza.

bledo antes de 1725 ya se hacían rogativas a la Virgen de la Caridad ${ }^{15}$ y se pagaban peonadas para su extinción, distribuyendo en 1727, 4.000 fanegas de canuto ${ }^{16}$ y 4.000 peonadas.

En 1731 en Munera se producen los primeros síntomas de la crisis que pondríamos en relación con las malas cosechas que desde 1734 a 1738 asolaron La Mancha. Así lo refería en 1738 un memorial del obispo de Cuenca: "...la mala esterilidad general que se ha padecido desde el año 1734 hasta el presente, en que se ha arruinado la más noble parte de esta diócesis, que es La Mancha, donde las labores se hallan reducidas en algunos lugares a la mitad, a la tercera y en otros a la cuarta parte de las que había en los antecedentes"17. María del Castillo en su testamento declaraba: "como el año 1734 fue tan malo y falto de granos para el alimento de nuestros hijos, fue preciso venderla" (la casa) ${ }^{18}$. Se puede decir que era el

15 Sobre las procesiones con la cabeza de San Gregorio en ciertos pueblos manchegos, véase: J. M. Palop, Hambre y lucha antifeudal. Las crisis de subsistencia en Valencia (Siglo XVIII), Madrid, Siglo XXI, 1977, pp. 88-90

16 Según el diccionario de la Real Academia, canuto es un tubo formado por la tierra que se adhiere a los huevos que la langosta y otros ortópteros depositan después de haber introducido verticalmente el abdomen en el suelo.

17 A. Domínguez Ortiz, Sociedad y estado en el siglo XVIII español, Barcelona, Ariel, 1976, p. 407

18 AHPA, Sección Protocolos notariales, caja 2210 de la villa de Lezuza. 
momento inicial de una crisis agraria derivada del cambio de coyuntura ${ }^{19}$ y que en 1738 aún se padecía. De hecho en la ciudad de Alcaraz en este año de 1738 se duplicaron los índices de mortalidad. En 1752 en Bienservida se decía que "muchos labradores y cosecheros para mantener sus familias an vendido parte de sus yuntas y ganados" y solicitaron al Corregidor de la ciudad un préstamo de granos, debido a las malas cosechas y repetidas lluvias ${ }^{20}$. La coincidencia entre periodos de aridez y plagas de langosta son múltiples, y desde mediados del siglo XVIII la langosta asoló tierras y cultivos: en 1755 en Villaverde, 1757 en Villapalacios y entre 1756-58 se extendió por el Campo de Montiel y Villarrobledo ${ }^{21}$.

Sin embargo, y a pesar de todo, el crecimiento natural de la población, durante el último quinquenio de la década sería positivo, gracias a la conjunción de una vigorosa nupcialidad y natalidad. Pero a partir de entonces la subida de los precios del trigo con la libertad de comercio de granos ${ }^{22}$, motivaría en 1766 otra grave crisis, con especial virulencia en El Bonillo (213 fallecidos). Prueba evidente de esta situación son las quejas por falta de trigo que en ese año presentaba al Consejo de Castilla la ciudad de Alcaraz, al igual que habían hecho otros pueblos manchegos y conquenses como Casas Ibáñez, Chinchilla, Tarazona de la Mancha o Iniesta ${ }^{23}$.

En 1774 fue especialmente intenso en lo que se refiere a la mortalidad infantil, sobre todo en la ciudad de Alcaraz, más de dos tercios de los registros de defunción eran de párvulos, siendo a finales de verano y principios del otoño los meses más afectados. En 1786/87 la sobremortalidad se cebó ahora en las aldeas de Alcaraz y villas manchegas, triplicando la mortalidad estimada como normal. Sus efectos se extenderían hasta principios de la década de los noventa, década que se iniciaría de nuevo con sobremortalidades catastróficas, y es que como apunta Reher, para el conjunto de Castilla La Nueva, es posible que a finales del XVIII nos encontremos frente a una de las típicas crisis malthusianas en la que el crecimiento habría superado los límites que podía soportar una economía agrícola poco dinámica ${ }^{24}$.

19 G. Anes, Las crisis agrarias en la España Moderna, Madrid, 1970, p. 429.

20 AMAlc, Leg 15, Exp.24 "Auto dado por el Corregidor de la Ciudad de Alcaraz para que el Posito de Bienservida ayude a los labradores debido a las malas cosechas" (28/04/1752).

21 J. Díaz Pintado, "Climatología de La Mancha durante el siglo XVIII", Cuadernos de Historia Moderna, $n^{\circ} 12$ (1991), pp. 146-148.

22 Los máximos precios de trigo en Castilla se dieron en 1765.

23 P. Losa Serrano, "Alcaraz en el Antiguo Régimen: aspectos sociales", en Congreso de Historia de Albacete, Vol. III, Edad Moderna, Albacete, IEA, 1984, p, 131, coincidente con las demandas de corregidores y alcaldes mayores ante el Consejo de Castilla de una legislación favorable para los labriegos.

24 D. Reher, Dinámicas demográficas en Castilla la Nueva, 1500-1900: un ensayo de reconstrucción Instituto de Demografía, Serie Documentos, Madrid, CSIC, 1990, p. 44. 
Sin embargo, esta centuria, aunque con una trayectoria irregular y escalonada, las distintas combinaciones de nupcialidad, fecundidad y mortalidad daban un balance positivo y el desarrollo demográfico tendió a ser progresivamente autosostenido en el Partido de Alcaraz (Gráfico 2).

\section{GRÁFICO 2}

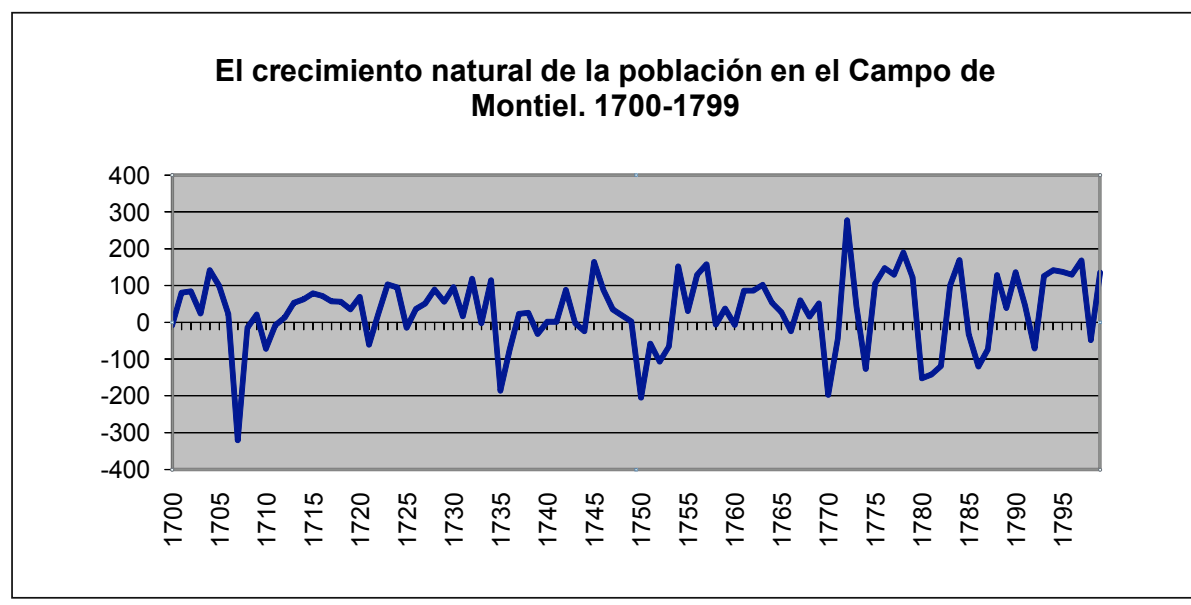

Fuente: ADA, Libros de bautismos y defunciones de El Bonillo, Lezuza, Munera, Balazote, Barrax y Lezuza.

\subsection{Entre la crisis y la recuperación. $1800-1830$}

La tendencia y dificultades señaladas en los últimos años del siglo XVIII continuaron en los primeros años de la siguiente centuria, agravados aún más por la crisis de 1804/05 y el impacto de la Guerra de la Independencia. Años marcados por una profunda crisis agraria combinada con una terrible sobremortalidad epidémica ${ }^{25}$. Así lo certificaban los médicos comisionados de visita por La Mancha, figurando entre las poblaciones más afectadas El Bonillo, Lezuza, Barrax, Munera y Villarrobledo. Concretamente la epidemia debió iniciarse en 1803 por las elevadas cifras de defunciones (Tabla 2).

En 1809 y 1813 se asistirá a un calamitoso quinquenio salpicado por el hambre y algunas acciones bélicas esporádicas. Tal y como refleja el gráfico 3 la epidemia trajo una terrible mortandad a estas tierras. El

25 A este respecto véase M. García Ruipérez, Revueltas sociales, hambre y epidemias en Toledo y su provincia. La crisis de subsistencias de 1802-1805, Toledo, 2000. 
Bonillo superaba las 600 defunciones en estos tres años y en Munera se contabilizan 505. El paludismo constituyó la principal causa de mortalidad durante muchos años.

\section{TABLA 2}

CRISIS DE MORTALIDAD EN LA PRIMERA MITAD DEL SIGLO XIX ViLLAS DE La MaNCHa ORIENTAL (1800-1838)

\begin{tabular}{ccc}
\hline Años & $\mathrm{N}^{\circ}$ fallecidos & Intensidad \\
\hline 1803 & 731 & 177 \\
1804 & 794 & 201 \\
1831 & 546 & 156 \\
1834 & 642 & 164 \\
1838 & 541 & 184 \\
\hline
\end{tabular}

Fuente: Libros de defunción de las villas El Bonillo, Lezuza, Munera, Balazote, Barrax y Lezuza.

En 1803 la miseria de la población en el marco de una crisis general desencadenó un incremento de fiebres tercianas en el verano de 1803 que desembocó en el verano de 1804 en una violenta epidemia, tanto es así que el párroco de El Bonillo certificaba que algunos enfermos recibían los santos sacramentos, pero no la sagrada Eucaristía pues el enfermo estaba alertagado ${ }^{26}$. El gráfico siguiente es muy ilustrativo de la dramática situación de estos años.

Alcaraz fue durante la Guerra de la Independencia cuartel General que albergaba el batallón 42 de voluntarios realistas y en Elche de la Sierra se encontraba la Junta de la Mancha, además el terreno era propicio para la guerra de guerrillas y fue objeto de varios combates ${ }^{27}$. No obstante los datos para 1808 y 1815 aportados por Higueruela del Pino $^{28}$ desde el punto de vista demográfico no son todo lo negativos que cabría esperar,

26 Archivo Parroquial de El Bonillo, Libro BON 60 (de 1790- 1806), firmado por don Antonio Luxán el 27 de julio de 1804

27 Así el 22 de noviembre de 1810 el gobernador y jefe de las tropas francesas de La Mancha, Lorgé, ordenó al coronel Nassau que marchara contra las bandas de guerrillas que no dejaban de extraer granos y atacar destacamentos franceses, por ello desde Villanueva de los I. Losa Serrano, “Alcaraz en el Antiguo Régimen: aspectos sociales”... op. cit. pp.119-151.

28 L. Higueruela del Pino, La Diócesis de Toledo durante la Guerra de la Independencia española, Toledo, Caja de Ahorros de Toledo, 1982, pp. 261-262. 
pues salvo Alcaraz y Bienservida, con 39 y 20 vecinos menos que en el primer año de referencia, el resto de poblaciones sobrepasaba la cifra inicial. Con todo, Vicente Pérez Moreda ${ }^{29}$ estima en unas setecientas u ochocientas mil personas las pérdidas del potencial crecimiento demográfico de la población española durante los años transcurridos entre 1797 y 1815.

\section{GRÁFICO 3}

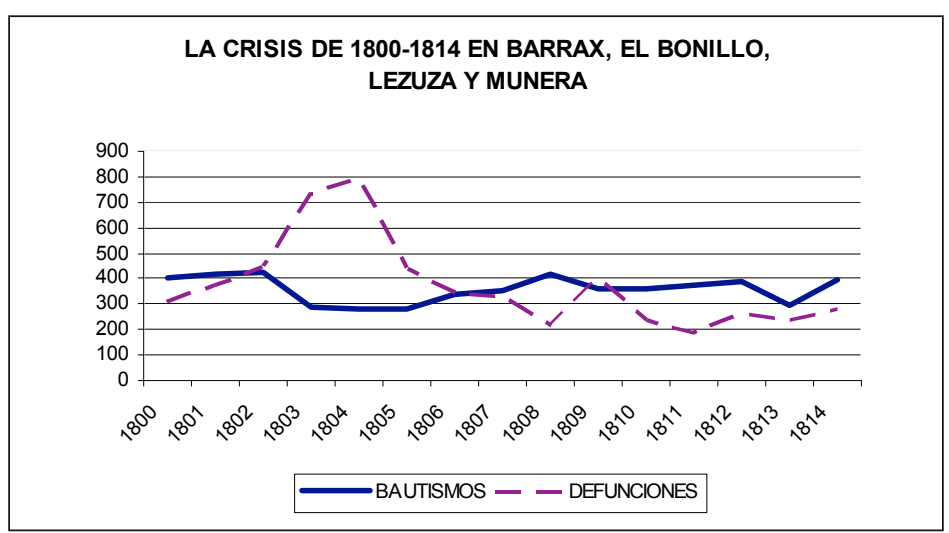

Fuente: Libros sacramentales de las villas de Barrax, El Bonillo, Lezuza y Munera entre $1800-14$

Este dramático periodo entre los años finales del siglo XVIII y el XIX contribuirían a consolidar un desarrollo regional de la población muy diferenciado, en el que las zonas del interior perderían parte de su peso específico poblacional en el conjunto nacional, y paralelamente se produciría la desurbanización de estas tierras ${ }^{30}$. En realidad la crisis afectó a toda la península y el retroceso que sufrió la zona central y todo el interior en los primeros quince años del siglo XIX queda registrado como el ciclo depresivo más intenso y prolongado de cuantos pueden apreciarse desde 1700. Si bien es cierto que su recuperación fue rápida ${ }^{31}$, y que los años posteriores a la guerra supondrían desde el punto de vista del creci-

29 V. Pérez Moreda, "Crisis demográfica y crisis agrarias: paludismo y agricultura en España a finales del siglo XVIII”, en Congreso de Historia Rural. Siglos XIV al XIX, Madrid, Universidad Complutense de Madrid-Casa Velázquez, 1984, pp. 333-354.

30 En Castilla-La Mancha sólo había 25 núcleos que superaban los 5.000 habitantes, y la mayoría de la población residía en pueblos con una población comprendida entre las 500 y 2000 personas en F. García González, "La población y la familia en tiempos de crisis", en J. S. Pérez Garzón (coord.), España 1808-1814. De súbditos a ciudadanos, Toledo, JCCLM, 2009, tomo I, p. 87.

31 V. Pérez Moreda, "El legado demográfico del Antiguo Régimen", en VII Encuentro de didáctica de la historia económica. Murcia, 12-13 de junio de 2003. 
miento demográfico, un periodo excepcional y vertiginoso. En la ciudad de Alcaraz, entre 1787 y 1830 se creció a una tasa del 1,33 por ciento y hacia 1824 se superaban ampliamente los niveles alcanzados en el siglo XVI. Las aldeas evolucionaron a un ritmo ligeramente inferior $(1,23)$.

\section{LOS LÍMITES DEL CRECIMIENTO. ESTRUCTURA AGRARIA Y DEPENDENCIA}

Los obstáculos para el crecimiento de la población no desaparecieron con el nuevo siglo. Obstáculos derivados de una estructura social y política inadecuada, con la presencia de grandes propietarios que no miraban hacia la tierra y la agricultura, como así expresaba el cura párroco de Viveros a la pregunta 12 de las Relaciones del Cardenal Lorenzana: "pocos labradores que hai cultivan tierras agenas, cuias rentas les empobrecen, tienen criados que llaman muleros o gañanes... y en réditos y soldadas se invierte el producto de sus labores" 32 .

Obstáculos políticos también serían claves para explicar el escaso dinamismo demográfico, como en las villas del señorío de Paredes, donde sus vecinos se quejaban de la "servidumbre que ace muchos años padecen por la mala versación de los caudales públicos y de los positos... ya que... con sola la buen administración de los caudales públicos y positos, que su fondo es bastante, tendrían un adelanto conocido, asi en el mas vecindario, como en los caudales" ${ }^{3}$. Además, y no menos importante, era el hecho de que numerosos núcleos de población, no contaban con término independiente, de ahí que de nuevo el cura de Viveros indicase la necesidad de hacerse villa "perdonando los derechos o costas". Tampoco debemos olvidar las limitaciones sobre roturaciones y utilización del espacio comunitario. Seguía vigente el capítulo 13 de las Ordenanzas de la ciudad de Alcaraz para la conservación de montes, dehesas y término, aprobadas en 1660, en las que se indicaba que "ninguna persona puede hazer en los dichos montes, sierra y dehesa arroturas, ni rompimientos ni ensancharse en las heredades que tuvieren, ni cortar ni quemar árboles ningunos para hazer dichos rompimientos" ${ }^{34}$, o las Ordenanzas de Marina relativas a la explotación del monte que vedaba el ramoneo y ponía enormes dificultades para la entrada de los rebaños.

Respecto a los ganados, tampoco parece ser que resultaban muy productivos, dado que sus beneficios, al menos los de la leche, se lograban en otras partes y no contaban con pastos frescos, según indicaban en el

32 R. Sánchez González, "El Partido de Alcaraz.. op, cit, p. 74.

33 Archivo del Palacio Real, Leg. 656. "Expediente formado sobre la compra de el Señorío de las Cinco Villas de Riópar, Villaverde, Cotillas, Bienservida y Villapalacios”.

34 Archivo Histórico Nacional, Consejo de Castilla, Serie: Rompimientos de tierras, siglo XVIII. Ciudad de Alcaraz, Leg. 10506. Averiguaciones sobre rompimientos de tierras, 16/07/1752. 
Catastro de la villa de El Bonillo, "teniendo que sacar dicho ganado a agostar fuera de este término. Su finalidad principal, además de la venta, era la producción de lana, y de carne, ...ni hacer queso de esta especie de ganados ni de otra alguna, cuyos beneficios logran en otras partes" 35 .

Como consecuencia de todo ello, difícilmente se podía asegurar un crecimiento vegetativo acumulado para garantizar la reproducción de la población en esta comarca. Y es que el Partido de Alcaraz a finales del Antiguo Régimen nos ofrece una imagen agrícolamente deprimida debido a la infrautilización de su territorio y su baja productividad. Caracterizada por la existencia de enormes extensiones de tierras de secano, poco profundas y condicionadas en gran parte por su extrema aridez, se mantenía un sistema agrario muy arcaico y poco diversificado. Se puede hablar de un auténtico monocultivo cerealista, grandes extensiones de sembradura de cereal constituían sin paliativos la dedicación predominante. Estimamos que sobrepasaba el 96 por ciento en la zona manchega, el (40,27 de la tierra era productiva) y más del 97 en la comarca de Alcaraz, aunque solamente el 28,36 por ciento de la superficie comarcal en Alcaraz estaba cultivada, frente al 71,64 que eran tierras incultas ${ }^{36}$.

Junto al monocultivo del cereal, la vid supuso una alternativa a la crisis completando las economías agrícolas y será en el siglo XVIII cuando se pongan las bases del desarrollo posterior, sobre todo en la zona manchega del Partido. El Bonillo destinaba 745 hectáreas al viñedo lo que le permitía la venta de vino a las localidades vecinas, ya desde los tiempos de Felipe II, exportaba pan y vino a las villas de La Mancha ${ }^{37}$. Y en 1786 se decía que su mayor cosecha era de vino, tanto es así que el concejo de la ciudad exigiría, como se pone de manifiesto en sus Ordenanzas, poner viñas a los nuevos pobladores que se instalaran en el campo de Barrax. En cambio en la zona montañosa de la sierra de Alcaraz la superficie destinaba a la vid no llegaba al uno por ciento (unas 540 hectáreas en menos de mil parcelas).

Pero la estructura agraria estaba marcada por su profundo desequilibrio, y poblaciones como Villarrobledo tenían el 53 por ciento de propietarios que no alcanzaban el uno por ciento de la tierra, mientras que solo un 6 acaparaba el 82. En El Bonillo sucedía lo mismo, el 61 por

35 AHPA, Sección Catastro de Ensenada, Libro 104 de la villa de El Bonillo.

36 Para darnos una idea más amplia, para todo el sector Noroeste de la provincia de Albacete, incluyendo Villarrobledo, solo sería un 51 por ciento las tierras roturadas según A. Cebrián Abellán, El catastro del marqués de la Ensenada en el contexto del siglo XVIII. Análisis socio-económico e interpretación espacial. Tesis doctoral. Universidad de Murcia, 1983, pp. 24 y 35.

37 C. Viñas Mey y P. Ramón, Las Relaciones de Felipe II Relaciones histórico-geográficoestadísticas de los pueblos de España hechas por iniciativa de Felipe II. Provincia de Ciudad Real, Madrid, CSIC, 1971. 
ciento de los propietarios sólo reunía el 2,5 de la tierra y en la comarca de Alcaraz únicamente el 17 por ciento de los propietarios superaba los mil reales de producto estimado.

Por lo tanto una minoría, entre las que se encontraban los concejos, el clero secular y regular y una reducida élite de grandes propietarios eran los dueños de una abrumadora proporción de tierra. La consecuencia no podía ser otra que el escaso aprovechamiento del suelo, con el predominio de unas fuentes de ingresos muy primarias, basadas en la combinación de una agricultura y de una ganadería extensivas con la explotación del monte. Pero además el resultado de esta situación llevaba a la existencia de unos estrechos lazos de dependencia para un abultado número de jornaleros, mozos de labor o de ganado.

Diferencias sociales y económicas que condicionaban asimismo la estructura y tamaño de los hogares, pero también la casa y hasta el incipiente conjunto urbano, de ahí que este análisis se complete con el estudio de la vivienda, calles y hogares que las conforman.

\section{UNA IMAGEN DE LAS DIFERENCIAS: CALLES, CASAS Y HOGARES}

\subsection{Urbanismo y sociedad}

Si hemos de buscar un lugar donde con mayor evidencia se muestran las diferencias sociales este era la calle Mayor, lugar de residencia de las élites, de los labradores, de los criados del servicio doméstico, de tenderos y comerciantes, de maestros artesanos, jornaleros, abogados, mozos sirvientes y de gran número de viudas. Verdadero escaparate social que debido a la extensión de la misma -en El Bonillo y Munera, por ejemplo atravesaba los núcleos urbanos de un extremo a otro- su largo trazado permite que todos los grupos sociales, se den cite en ella, como actualmente ocurre en las grandes ciudades del mundo desarrollado.

Pero también es cierto que la mayoría de los lugares urbanos aquí considerados, nunca fueron "proyectados", por lo que sería inexacto hablar de planeamiento urbano o urbanismo. Las primeras representaciones gráficas de la morfología urbana de estas villas las encontramos en el Catastro de Ensenada. (Anexo planos 1, 2 3). El método de representación de estos dibujos era el tradicional, se hacía resaltar la iglesia y los edificios eclesiásticos, o como sucede en Balazote resaltaban la casa del señor conde, sobredimensionadas con respecto al resto de los edificios. El crecimiento urbano estará ligado al comportamiento demográfico experimentado en cada villa. La planimetría se estructuraba a partir de la plaza principal, presidida por la iglesia parroquial 
desde donde partían las distintas calles principales que enlazaban con otras vías secundarias.

Alcaraz, cuna del arquitecto Andrés de Valdelvira, fue en el siglo XVI cuando la ciudad adquirió un importante conjunto urbanístico ${ }^{38}$ y se dotó de un nuevo centro urbano, la Plaza Mayor, alrededor de la cual giraba toda la vida de esta ciudad. Su trazado urbanístico y disposición de las calles, era un fiel reflejo de las condiciones topográficas, así como de sus circunstancias históricas y sociales. La forma y los cambios urbanísticos en la zona descansaron, en gran medida, en la construcción promovida por las élites sociales, en los edificios religiosos, iglesias, ermitas, conventos, casas de las obras pías o cofradías. Aquí como en la mayor parte de los pueblos castellanos los grupos de élite no sólo marcaban con sus edificaciones el territorio que ocupaban, sino que se distribuían por las calles o plazas céntricas de estas villas, y en algún caso toda la calle les pertenecía, porque, el poder y el prestigio se deben conquistar y exhibir cotidianamente ${ }^{39}$.

Los concejos gestionaban las rentas y los gastos públicos, tanto en reparos como en nuevas construcciones de edificios. Y en consonancia con la política de la época, se traba de cubrir las necesidades básicas de los vecinos y mejorar el equipamiento urbano.

Los Autos de buen gobierno a través de sus ordenanzas municipales, trataban de mantener el orden y la buena armonía dentro de cada villa, pero a pesar de ello las actuaciones municipales no respondían a planes organizados previamente, sino que eran repuestas ante los problemas planteados, se trataba de intervenciones puntuales para la mejora de los equipamientos del común.

En 1788 se solicitaba al señor fiscal el recurso hecho por la Junta de Propios del Lugar de Salobre, "solicitando permiso para empedrar la plaza, calles y demás sitios intransitables" ${ }^{0}$. Dos años después el lugar de Viveros solicitaba también el empedrado de la calle frente al pilar, pero indicaban, "que se costee dicho empedrado entre los vecinos pudientes satisfaciéndose del caudal sobrante de propios la partes que corresponda ${ }^{41}$ y en Viveros, (1790) el regidor del lugar Ramón Galdon

38 Así en 1518-19 se construye el convento de santo Domingo o Lonja del Corregidor, allanamiento y empedrado de la calle Mayor (1518-1527), levantamiento dela torre de la Trinidad (1544), levantamiento de la torre del Tardón (1555-1568?-1574?), restauración de numerosos edificios públicos y arreglo de algunas calles (1576), construcción del alhorí (1588), construcción de la lonja de la Regatería, también llamada Casa del Corregidor (1592).

39 G. Auguntins, "Jerarquización social y señas de diferenciación: el caso de Évora en Portugal”. Revista de Antropología Social, no 12 (2003), pp. 121-142.

40 AMAlc, expediente 514, legajo 31 de Alcaraz.

41 AMAlc, expediente 514, legajo 31 de Alcaraz. 
insistía en la "necesidad de reparar y limpiar el lavadero" 42 y es que las condiciones higiénicas eran deplorables, los animales se sacrificaban en la calle, principalmente en verano. En Lezuza, el informe emitido por el alarife Domingo de Coca, en 1792, indicaba que el cuarto que hace de carnicería “...encuentro ser un tercio de cuarto a texa vana, demasiado indecente, y muy reducido para dicho fin, y que dicha matanza por la corta extensión, tienen que hacerla en la calle, y en tiempo de temporal dentro de dicho cuarto, lo que trayendo los olores en toda la calle, siendo de gran perjuicio, y debiendo estar al reparo" ${ }^{43}$, por lo que también intervenían en temas de salud pública y edificios (horno de pan de cocer, carnicería, ayuntamientos, cárcel, casa del pósito, casa de la tercia...). En este sentido traemos la queja que en 1751 un grupo de grandes propietarios de ganado de Alcaraz elevaba al Corregidor sobre la pobreza en que estaba sumida la ciudad en comparación a períodos anteriores cuando se disponían de "caudales Publicos con tanta opulencia que se pudieron construir las ylustres Obras Publicas que se manifiestan y que al presente no se pueden mantener". Esta misma sensación volvía a confirmarse quince años después a tenor de lo expuesto por el Procurador Síndico del Común en el mes de junio de 1766 cuando señalaba que "es publico y notorio que esta Poblacion se alla muy deformada en sus casas y edificios, con grabes contingencias de ruynas y daños,.. y que los tales detrimentos y deterioros por lo grâl se allan sin reformarse por la pobreza o cortedad de medios de los dueños" ${ }^{44}$. Por ello se pedía que se hiciera un reconocimiento general de las casas que necesitaran reparos "precisos a su subsistencia con individualidad de sus situaciones, calles, piezas que deban repararse, sus dueños y cantidades que sean precisas para su perfecta permenencia" 45 .

\subsection{Casas y hogares}

En relación a la vivienda, las respuestas a la acción climática, son similares en toda la zona; hay que buscar la mayor protección frente al calor o el frío, de ahí la casa encamarada de mayor o menor superficie, pero presente en prácticamente todas las villas. Además gruesas paredes de tapial y algunas de piedra con escasos vanos y buena orientación hacia el saliente, contribuían a encontrar un equilibrio sostenible entre edificación y medioambiente, con técnicas totalmente bioclimáticas y

42 AMAlc, expediente 514, legajo 31 de Alcaraz.

43 AMAlc expediente de obras 514, legajo 31 de Alcaraz.

44 AMAlc, legajo 380, Pedimento de los ganaderos al Corregidor (14-07-1750).

45 AMAlc, legajo 380 expediente suelto con fecha 16-6-1766. 
materiales del entorno ${ }^{46}$. La casa manchega, presentaba unas dimensiones, por término medio, cercanas a los 120 metros cuadrados, dimensiones que ocultan realidades muy diferentes. Junto a casas con una superficie superior a los 200 metros cuadrados, aparecen otras muy pequeñas, cuya superficie en planta no alcanzaba los $20 \mathrm{~m}^{2}$. Estas casas constaban de un solo cuarto, el cual cumpliría todas las funciones, desde cocina o sala a dormitorio, con un patio o corral. Se puede considerar el modelo general más antiguo que desde el siglo XVI nos encontramos en La Mancha y en la Castilla meridional, casas bajas, pobres, muy sencillas arquitectónicamente y de una gran austeridad. Solían ser de una sola planta con un cuerpo común y unitario y casi nula compartimentación, predominando los de una sola dependencia. Espacios reducidos, no cerrados ni divididos ni diferenciados, donde tabiques, pasillos y puertas casi no existían y en los que los miembros de la familia convivían hacinada y cotidianamente con animales y herramientas, dando lugar así a una gran promiscuidad ${ }^{47}$. En Munera Francisco Santos tenía una casa en la Calle Temeridad que consistía en una cocina colgadiza de $11 \mathrm{~m}^{2}$. La mayoría de estas viviendas tenían un corral o patio, pero se trata de viviendas pequeñas, inferiores a los $50 \mathrm{~m}^{2}$ y con escasa o nula división del espacio doméstico.

En cuanto a la casa con dos plantas, casa encamarada, constaba de un cuerpo encamarado formado por un cuarto de cocina y un aposento con cámara. Así pues las dos piezas, aposento y cocina formaban el único cuerpo de la vivienda, la separación entre ambas sería un simple vano, que excepcionalmente se cubriría con algún tipo de cortina o puerta. Un segundo dormitorio encamarado y el descubierto o corral era una tipología también bastante habitual. Las casas de los grupos hacendados multiplicaban las estancias, en algunas se mantenía la cocina y aposentos (dos, tres e incluso más) y en algún caso se describe una sala, todo encamarado y a continuación las dependencias anejas: patio, descubierto y caballeriza. La sala es excepcional, "lugar de respeto, de muy poco uso 48 ". Don José Bartolomé Abarca nos describía una casa "con portal, cocina principal, sala con alcoba, otra sala y dos alcobas,

46 Pizarra, granito, piedra caliza, barro... Con los materiales de la tierra, los lugareños han levantado desde siempre casas que se adaptan mejor al clima y a sus necesidades que la mayoría de las construcciones modernas. Por fortuna, aún quedan pueblos en Madrid que recuerdan cómo era el mundo antes de los adosados y los arquitectos-estrella (El Pais.com. Andrés Campos, 21-09-2007).

47 F. García González, "La casa rural en Castilla meridional. Aproximaciones arquitectónicas y constructivas en la época del Quijote" en P. Sanz Camañes (coord.), La Monarquía Hispánica en tiempos del Quijote, Madrid, Universidad de Castilla La Mancha- Centenario Don Quijote- Ediciones Silex, 2005, p.114.

48 N. Hoyos Sancho, "La casa manchega" en Congres International de Geographie (Lisboa 1949), Lisboa 1951, tomo III, p. 124. 
dos dormitorios, una oficina". Todo encamarado; fuera de esta zona de vivienda se encontraba el patio, "un cuarto de cocina y de horno, caballeriza, pajar y un descubierto bastante grande". La casa se localizaba en la calle Mayor de Lezuza y tenía 750 metros cuadrados.

En la ciudad de Alcaraz, en cambio, un trazado de callejuelas tortusosas, oscuras, húmedas y poco ventiladas, en lamentable estado, tanto por la antigüedad como por la deficiencia de los materiales de construcción, presentaban viviendas, en su mayor parte pobres y apiñadas, "en termino que las chimeneas de unas casas tocan a las ventanas de otras" 49 . Algunas casas principales, sin embargo, como la del Corregidor, respondía a la tipología de vivienda con dos plantas, chimeneas, cuarto de estudio, ventanas e incluso vidrieras, celosías, y habitaciones diferenciadas por sexos. En noviembre de 1751 precisaban reparaciones y se da cuenta de ello en el presupuesto de obra:

“... en las puertas, ventanas y vidrieras y en el balcón del gabinete nos hemos ocupado tres días el maestro y un ayudante, importan los tres días veintiocho reales y medio. De clavos y tachuelas para asegurar las piezas que se fueron juntando en las vidrieras y ventanas, 4 reales. De una bisagra que se hizo nueva para las puertas de vidrios para el estudio, 4 reales. Para hacer la chimenea nos ocupamos un día el maestro y el oficial y un peón, ganamos 14 reales y medio. De armarla de madera y clavos, 10 reales. 8 fanegas de yeso a dos reales, 16 reales. De un tirante que se ha gastado para la chimenea del cuarto del estudio, 3 reales. De tres portaleñas, 3 reales. De un picaporte que se ha hecho nuevo, 7 reales. De tres docenas de clavos que se han gastado en clavar las tablas del balcón, 4 reales. De la celosía de madera, tachuelas y trabajo, 75 reales" ${ }^{50}$.

La casa reflejo de la sociedad, mantiene la férrea estructura del Estado Absoluto e impone a sus miembros una jerarquía estamentalizada. De ahí que en la planta baja, a pie de calle, en las casas principales, se alojaban los servicios de la casa, tales como las caballerizas o cocinas, sirvientes, cocheros o cocineras. No obstante, la realidad de estas villas es que sus viviendas no eran casas de muchos criados, entre otras razones porque su finalidad era más productiva que de ostentación, la media estaría en tono a 28 por cada 100 familias, lo que nos sitúa en los niveles más inferiores de los establecidos por Fauve-Chamoux y Richard Wall para Europa. Su presencia parece ser que era mayor en

49 P. Madoz, Diccionario Geográfico-Estadístico -Histórico de España y sus posesiones de ultramar, Madrid 1845-50, Ámbito ediciones, 1987, p. 107.

50 AMAlc, expediente 514, legajo 31 de la ciudad de Alcaraz. 
los pueblos del Señorío, tanto en Balazote como en los de las Cinco Villas, en torno al $10 \%$. Su distribución por sexo demuestra un claro componente masculino en su composición, dado que las tres cuartas partes eran varones, sobre todo en las aldeas de Alcaraz, El Bonillo, Lezuza o Munera.

Se trataba de un grupo de población joven, en torno al 60 por ciento de los criados y al 75 de las criadas tenían menos de 25 años. A partir de esta edad su presencia se reduce notablemente, coincidiendo con el matrimonio y así lo comprobamos en Villarrobledo, de los 368 criados de los que conocemos su estado civil no hay ninguna mujer casada entre ellos, mientras que el 31,5 por ciento eran varones que ya habían contraído nupcias. También es igualmente significativo que en Alcaraz y su jurisdicción el $28 \%$ de los criados superaran los 35 años. En El Bonillo, cerca del 40 por ciento de los varones y casi el 44 de las mujeres estaban en el servicio hasta los 24 años y de 25 a 34 años, los hombres se acercaban al 25, mientras que la mujer bajará a un 13 . Todo apunta a la continuidad del sirviente entre los varones a pesar de la edad y cómo esta actividad con frecuencia podía convertirse en algo permanente.

Varios factores se encontrarían detrás de esta situación. En un contexto marcado por la desigualdad en la distribución de la propiedad, la misma composición y tamaño de los hogares junto al sistema de transmisión igualitaria de los bienes, conllevaba muchas dificultades para hacerse con la gestión de una explotación solvente, lo que daría lugar no solo a excedentes laborales, sino también a un porcentaje de población netamente dependiente a lo largo de su vida. Pero si nos referimos a mujeres casadas es muy difícil que las fuentes nos informen de su trabajo en el servicio doméstico, de ahí que sean muy significativas las declaraciones del mayoral de mulas Andrés Cañadas Moreno, de Villarrobledo, quien a su 47 años indicaba que el oficio de su mujer Josefa Olivares de 36 años era "la servidumbre de casa de doña Elvira Romero, viuda de Francisco Téllez" a pesar de que tenían cuatro hijos menores de nueve años.

Y es que la vinculación de las mujeres a la vida doméstica ha implicado, en muchos casos, que se olvide su participación en la vida laboral. Activas, con o sin marido, su supervivencia dependerá en muchos casos de los ingresos derivados de su trabajo asalariado. Si eran viudas o de marido ausente el servicio doméstico no se descartaba, en caso de necesidad. Así Antonia María Estero, vecina de Villanueva de la Fuente, declaraba en 1738 que su marido se fue a Murcia en busca de trabajo por la "ynopia de los tiempos". Hasta 6 años después que falleció en 
Buitrago no supo nada de él, por ello "viéndose en tan dilatado tiempo sola, pobre y desamparada, viviendo como vivía inmediata a las casas de María Guerrera (que estaba viuda), fue llamada para socorrerla y ayudarle en los haceres de la casa por remuneración" 51.

Pero si entrásemos en estas viviendas, ¿qué familia encontraríamos? Lejos de encontrarnos con familias muy numerosas y muchos hijos, la realidad era muy distinta, los hogares eran más bien pequeños, en torno a los cuatro miembros $(3,91)$, si se contabilizan los criados. Si no se incluyen los sirvientes la media baja a 3,6 (Tabla 3).

TABLA 3

Tamaño y composición de los hogares. Partido de Alcaraz, 1752

\begin{tabular}{|c|c|c|c|c|c|c|}
\hline Población & $\begin{array}{l}\text { Tamaño } \\
\text { (con } \\
\text { criados) }\end{array}$ & $\begin{array}{l}\text { Tamaño } \\
(\sin \\
\text { criados })\end{array}$ & $\begin{array}{l}\text { Cabezas de } \\
\text { familia } \\
\text { y cónyuges }\end{array}$ & Hijos & Parientes & Criados \\
\hline Balazote & 4,11 & 3,62 & 1,71 & 1,76 & 0,15 & 0,48 \\
\hline Barrax & 3,73 & 3,61 & 1,69 & 1,80 & 0,10 & 0,11 \\
\hline El Ballestero & 3,60 & 3,41 & 1,72 & 1,59 & 0,09 & 0,19 \\
\hline El Bonillo & 4,04 & 3,65 & 1,62 & 1,83 & 0,20 & 0,37 \\
\hline Lezuza & 3,97 & 3,79 & 1,71 & 1,90 & 0,12 & 0,17 \\
\hline Munera & 3,72 & 3,66 & 1,68 & 1,93 & 0,05 & 0,05 \\
\hline Alcaraz ciudad & 4,27 & & 1,69 & 0,35 & 0,13 & 0,52 \\
\hline $\begin{array}{l}\text { Aldeas de } \\
\text { Alcaraz }\end{array}$ & 3,96 & & 1,69 & 1,88 & 0,13 & 0,25 \\
\hline Señorío 5 Villas & 3,89 & & 0,63 & 1,69 & 0,16 & 0,40 \\
\hline Bogarra & 3,78 & & 1,66 & 1,76 & 0,08 & 0,22 \\
\hline $\begin{array}{l}\text { Elche de la } \\
\text { Sierra }\end{array}$ & 3,94 & & 1,71 & 1,87 & 0,12 & 0,24 \\
\hline Villarrobledo & 3,98 & 3,66 & 0,69 & 1,82 & 0,13 & 0,33 \\
\hline Total & 3,91 & 3,62 & 1,51 & 1,68 & 0,12 & 0,27 \\
\hline
\end{tabular}

Fuente: Para la comarca de Alcaraz: F. García González, La sierra de Alcaraz en el siglo XVIII....op. cit.. Para Bogarra y Elche: M. P. Molina Gómez, Familia, población y propiedad de la tierra. Los jóvenes en la sierra del Segura albacetense del siglo XVIII, Trabajo de investigación para la obtención del DEA, Murcia, noviembre 2007; Para la zona de la Mancha: C. Hernández López, La casa en la Mancha oriental. Arquitectura, familia y sociedad rural (1650-1850), Tesis doctoral, Facultad de Humanidades, Albacete, 2009.

51 F. García González, "La ocupación del territorio. Familia... op.cit, p. 44. 
Es indiscutible que los promedios de hijos por hogar $(1,68)$ no son muy altos en general, pero son los responsables en gran medida del diferente tamaño de los agregados domésticos y sobre todo denotan el rejuvenecimiento de la población y vitalidad demográfica en las villas con mayor presencia, como son Munera o Lezuza.

Hogares que respondían al modelo de familia nuclear, rebasando el 77 por ciento, integrada por dos generaciones y residencia neolocal. La cohabitación de una tercera generación o de otros parientes era excepcional, en torno al 7,5 por ciento, cifra que se encuentra en consonancia con la estructura general de Castilla- La Mancha que no supera el 10 por ciento de los casos las familias complejas (Tabla 3).

TABLA 4

Estructura de los hogares. Partido de Alcaraz, 1752

\begin{tabular}{|c|c|c|c|c|c|}
\hline Población & $\begin{array}{l}\text { Hogares } \\
\text { solitarios }\end{array}$ & $\begin{array}{l}\text { Sin } \\
\text { estructura }\end{array}$ & Nucleares & Complejos & $\begin{array}{c}\text { Total } \\
\text { hogares }\end{array}$ \\
\hline Balazote & 7,96 & 0,88 & 78,76 & 12,38 & 113 \\
\hline Barrax & 13,27 & 1,89 & 78,59 & 6,23 & 389 \\
\hline El Bonillo & 13,91 & 4,23 & 72,78 & 9,07 & 992 \\
\hline Lezuza & 7,76 & 3,23 & 82,84 & 6,14 & 309 \\
\hline Munera & 12,39 & 0,43 & 84,56 & 2,6 & 460 \\
\hline Alcaraz ciudad & 10,6 & 3,4 & 75,1 & 10,7 & \\
\hline $\begin{array}{l}\text { Aldeas de } \\
\text { Alcaraz }\end{array}$ & 11,83 & 2 & 78,6 & 7,5 & \\
\hline $\begin{array}{l}\text { Señorío } 5 \\
\text { Villas }\end{array}$ & 17,7 & 3,3 & 70,5 & 8,4 & \\
\hline $\begin{array}{l}\text { Comarca } \\
\text { Alcaraz }\end{array}$ & 12,7 & 2,9 & 75,1 & 9,02 & 2450 \\
\hline Bogarra & 3,45 & 2,21 & 84,97 & 4,15 & 1132 \\
\hline $\begin{array}{l}\text { Elche de la } \\
\text { Sierra }\end{array}$ & 4,05 & 2,74 & 84,5 & 5,83 & 1606 \\
\hline Villarrobledo & 12 & 2,9 & 79,4 & 4,3 & 1454 \\
\hline
\end{tabular}

Nota: en Villarrobledo y en Bogarra habrá un 1,4 y un 5,9 por ciento de hogares indeterminados.

Los hogares solitarios por el contrario eran mucho más numerosos que los complejos, lo normal es que sobrepasaran el 10 por ciento (Casi un 
14 en El Bonillo). Datos que ponen de manifiesto dos realidades, por un lado la emigración de los jóvenes y por otra la muerte del esposo o de los padres, que forzarían a una situación de soledad a los que permanecen.

$Y$ es que las diferencias sociales y económicas condicionaban la estructura y tamaño de los hogares, aumentando el número de hijos, parientes y criados conforme se incrementaba el estatus, la categoría socio-profesional y los niveles de riqueza. De hecho el tamaño del hogar entre las familias hidalgas, clero y los poderosos aumentaba debido a la alta presencia de parientes y criados, como rasgo distintivo de prestigio social registrándose familias de seis, siete o más miembros, mientras que las familias solitarias o muy reducidas, por debajo de tres componentes, predominaban entre las viudas, mozos de labor y otros grupos desfavorecidos.

$\mathrm{Y}$ en este sentido debemos tener presente que nos encontramos en una de las zonas más proletarizadas de España, sobre todo en la comarca manchega donde el 22 por ciento de los cabeza de familia se inscribían como jornaleros, ganaban de utilidad diaria dos reales "teniendo presente el tiempo que no trabajan por fiestas y malos temporales y no haber donde trabajar" ${ }^{52}$. Una elevada proporción, como ya se decía en las Relaciones Topográficas, de "la gente es pobre sin trastos ni granjerías, sino solo la labor", pero labor en cuanto a trabajo en el campo, ya que la tierra se encontraba enormemente concentrada. Además considerar a todos los labradores por igual sería un error, pues entre ellos había una gran diversidad de fortunas y situaciones, desde los hacendados, propietarios de bueyes o mulas de labor y pollinos, hasta los que vivían al amparo de aparcerías con otros grandes propietarios, como ocurrirá en Munera. También se menciona en el Catastro el labrador sirviente, con la categoría de mayoral, zagal o ayudador. Trabajaban para los labradores propietarios, quienes a su vez empleaban mano de obra fija asalariada, cuando el patrimonio era el suficiente para tener varios pares de mulas.

En la escala social se encontraban además toda una variada gama de situaciones que ponen de manifiesto que el estatus y el tipo de economía familiar influirían sin duda en las dimensiones de la vivienda o la calle donde se ubiquen (Tabla 5).

Las élites, ocupaban las principales calles en todas las villas, en total se contabilizan 85 viviendas en las principales calles de la comarca manchega. La superficie media era de 603 metros cuadrados y la renta media estimada era también la más alta para todas las categorías analizadas, 173 reales.

52 AHPA, sección Catastro del Marqués de la Ensenada, villa de El Bonillo, libro 54 Repuestas Generales, $n^{\circ} 35$. 
TABLA 5

SUPERFICIE MEDIA DE LAS CASAS PROPIAS DE LOS CABEZA

DE FAMILIA POR CATEGORÍAS SOCIO-PROFESIONALES.

Villas de La MaNCHa ORIENTAL, 1752

\begin{tabular}{lrrr}
\hline GRUPO & \multicolumn{2}{c}{$\begin{array}{c}\text { Superficie Media, } \\
\text { en m}^{2}\end{array}$} & $\begin{array}{c}\text { Renta media en } \\
\text { reales }\end{array}$ \\
\hline Artesanado & 222 & 119 & 68 \\
Comerciantes & 56 & 168 & 60 \\
Clero & 61 & 165 & 99 \\
Elites & 85 & 603 & 173 \\
Forasteros* & 18 & 163 & 104 \\
Jornaleros & 283 & 104 & 49 \\
Labradores & 437 & 223 & 82 \\
Mesero & 9 & 140 & 56 \\
Menores & 26 & 94 & 46 \\
Mujeres & 293 & 167 & 52 \\
Profesión liberal & 39 & 220 & 90 \\
Sin oficio & 45 & 114 & 69 \\
Sirvientes & 174 & 115 & 55 \\
\hline Total & 1.748 & 2.395 & 1.003 \\
\hline Total media & & 184 & 77 \\
\hline
\end{tabular}

Fuente: AHPA, Sección Catastro del Marqués de La Ensenada, Libros: 39, 40, 42,57, 106, 141, 150 y Libro 36, $2^{\mathrm{a}}$ parte.

Nota: Con forasteros nos referimos a todos los propietarios de viviendas en las zonas analizadas y que no son vecinos de estas villas.

A los profesionales liberales les correspondían 39 viviendas. Un número muy bajo a todas luces denotativo de la escasa presencia de estos trabajadores en la zona. En el conjunto total de la comarca, presenta una superficie media de $220 \mathrm{~m}^{2}$.

En el total de la zona manchega el número de casas pertenecientes a miembros de la iglesia, capellanías, ermitas, cofradías o religiosos era de 61 , en general, viviendas de dimensiones grandes o medianas, la superficie media se estima en $165 \mathrm{~m}^{2}$. 
Los tenderos, arrieros, carreteros, tratantes y comerciantes en general, poseían un total de 56 casas. Por lo general, y con buena lógica, los tenderos se instalaban en las calles más concurridas y transitadas, así se evidencia en El Bonillo y Barrax. La media para ellos era de $168 \mathrm{~m}^{2}$ y 60 reales de renta anual.

El número de casas pertenecientes al mundo del artesanado era de 222. Son un colectivo minoritario en la comarca, su presencia se vinculaba a manufacturas de consumo local y con escasa proyección de mercado. La superficie media de sus viviendas era de $119 \mathrm{~m}^{2}$, si bien las diferencias entre ellos eran notables, sobre todo en el caso de las casas correspondientes a los alarifes y sastres, mucho mayores que las del resto de artesanos.

Los labradores poseían un total de 437 viviendas. En la calle del Pozo de la Cañadilla en Munera se concentraban 20 viviendas de labradores. Datos que si por una parte evidencian de nuevo el tipo de economía predominante, por otro nos ofrecen la visión de cómo determinadas calles serán prácticamente ocupadas por núcleos familiares pertenecientes a un mismo oficio, e incluso a una misma familia. Por lo general tenían casas grandes o muy grandes, la superficie media era de $223 \mathrm{~m}^{2}$, siendo especialmente amplias las de la villa de Barrax con $382 \mathrm{~m}^{2}$ en cambio en Munera tenían tan solo $64 \mathrm{~m}^{2}$.

En cuanto a las mujeres, las diferencias entre el tamaño de sus viviendas eran muy acusadas, desde 11 metros cuadrados que tenía la casa de Luisa López en Munera a los $214 \mathrm{~m}^{2}$ de la casa de Catalina Gómez en esa misma población. En general, la media de vivienda era de $167 \mathrm{~m}^{2}$, para las 293 viviendas de mujeres, viudas o solteras, pero cabeza de familia en esta comarca. La renta anual estipulada era de las menores, 52 reales al año.

Los jornaleros poseían un total de 283 viviendas propias, con una superficie media de $104 \mathrm{~m}^{2}$. Se instalan, por lo general en calles bastante concurridas. La media de superficie en Munera eran $43 \mathrm{~m}^{2}$, similar a los de la villa de Lezuza, $48 \mathrm{~m}^{2}$, en cambio en El Bonillo disponen de viviendas muy amplias, con una media de $131 \mathrm{~m}^{2}$ y en Barrax, $152 \mathrm{~m}^{2}$.

Finalmente los mozos sirvientes registran un total de 174 viviendas con 115 metros cuadrados de superficie media. Se instalaban en todas las calles, pero especialmente los encontramos en la periferia de las villas. En Barrax disponían de viviendas amplias, superiores a los 200 metros cuadrados, pero en Munera y Lezuza no llegaban a los $50 \mathrm{~m}^{2} \mathrm{y}$ en El Bonillo superaban los 125 metros cuadrados.

Datos que se corresponden con la estratificación de la pirámide social. Así, a mayor nivel económico y profesional, le correspondía una 
casa más grande y conforme descendemos en la escala social, la casa va igualmente haciéndose más reducida, a pesar de que en La Mancha y, en concreto, en esta parte oriental, la mayoría de las casas superaban los $100 \mathrm{~m}^{2}$. La media de superficie se estima en $184 \mathrm{~m}^{2}$, siendo la renta media anual para la comarca de 77 reales.

$\mathrm{Y}$ es que para los poderosos rurales el mantenimiento de su posición social diferenciada a lo largo del tiempo implicaba el desarrollo de calculadas estrategias familiares de perpetuación social. La vinculación de bienes en forma de mayorazgos, capellanías.. y otras prácticas dieron como resultado que ininterrumpidamente ocuparan el vértice de la pirámide en las villas y ciudad de este Partido.

Los grupos intermedios por su parte, se verán afectados igualmente por procesos de movilidad ascendente o descendente, son un gran número de familias y hogares pertenecientes a diversas categorías socioprofesionales, con muchas dificultades para mantener su posición.

Entre los grupos más precarios es difícil hablar de reproducción, a no ser la propia pobreza, pero al menos entre el artesanado, la continuidad de oficio garantizaba ante todo una calculada política de alianzas y del sistema de herencia, sistema que por regla general favorecía a los hijos varones, continuadores de la profesión paterna. En todo este entramado además, las relaciones de parentesco fueron fundamentales en el siglo XVIII y en la primera mitad del XIX -entre las familias de la oligarquía, los artesanos, profesionales liberales o labradores- para el posterior ascenso social en la primera mitad del XIX y esta situación aunque produjo la renovación de parte de la clase dirigente en la comarca, no se tradujo quizá en una transformación de las prácticas sociales y de los hábitos del parentesco ${ }^{53}$.

53 Tesis que defiende para el mundo urbano Juan Cruz y que habría que indagar más en el medio rural, véase: J. Cruz, Los notables de Madrid, Madrid, Alianza Editorial, 2000, p. 260. 
